Frøydis Vasset, førsteamanuensis, Avdeling for helsefag, Høgskolen i

Ålesund

\title{
Bedre helsetjenester i kommunen
}

\author{
Hvordan kan vi gjøre kommunehelsetjenesten bedre for brukerne etter samhandlingsreformen?
}

$\mathbf{N}$ år organisasjoner skal forbedres vil det være fornuftig å ha en mening om hvem den skal forbedres for og hvilke tiltak som er mest hensiktsmessig å anvende. I denne artikkelen vil jeg gjøre rede for hva som bør vektlegges for å øke kvaliteten på arbeidet i kommunehelsetjenesten.

\section{Økt ansvarsområde}

Gjennom flere tiår har kommunehelsetjenestens arbeidsoppgaver økt i tillegg til fagansvar for flere pasientgrupper som tidligere var et statlig ansvar. Denne omdelegeringen har vært nødvendig for å løse sammensatte helseproblemer i et komplekst samfunn. Pleie- og omsorgsdelen av kommunehelsetjenesten er hovedsakelig det arbeidet som blir gjort i sykehjem, omsorgsboliger eller hjemmesykepleien.

\section{Hovedbudskap}

Det er lett å trå feil når nye reformer blir innført. Kommunehelsetjenesten er spesielt sårbar fordi tjenesten ivaretar pasienters helse. Den største pasientgruppen er eldre brukere, ofte med komplekse lidelser og demens. Man bør i større grad vektlegge kompetansen hos helse- og sosialpersonell.

\section{Nøkkelord}

Les mer og finn litteraturhenvisninger på våre nettsider. | Organisering | Ledelse | Samhandling
Skal man forbedre eller gjøre en tjeneste mer effektiv må man først se på hvem den skal forbedres for. Skal det være bedre arbeidsvilkår og faglig utvikling for de ansatte, bedre $ø$ konomi og ressurser for organisasjonene eller er det pasienten som skal ha bedre pleie og omsorg? Ifølge Orvik (1) kan man ikke se disse faktorene atskilt hvis man skal forbedre helsetjenesten.

En rekke handlinger kan til sammen bedre kvaliteten på det arbeidet som blir gjort $\mathrm{i}$ kommunehelsetjenesten. Den normative verdipyramiden til Orvik (1) kan brukes som en modell for å skildre de ulike komponentene i helsetjenesten.

\section{Trenger mer kompetanse}

Om lag 95 prosent av pleiepersonalet i kommunen er kvinner (2). De fleste av dem er sykepleiere og hjelpepleiere, men kommunene har også ufaglært arbeidskraft.

Ny forskning fra USA indikerer at sykepleiere bør ha etterutdanning i ledelse på alle ledelsesnivåer for å ta hånd om et helsevesen $\mathrm{i}$ endring. Avdelingsledere og teamledere er også i frontlinjen i lederteam, avdeling eller etat samtidig som de ivaretar pasientbehandling (3).

En amerikansk undersøkelse viser at den ledelsesstrategien som brukes i omsorgstjenesten også kan ha en viktig innflytelse på pleiens kvalitet. Det vil si den kliniske og den organisatoriske kompetansen $(1,4)$. Forskning viser at ledelsen i hjemmebaserte tjenester i gjennomsnitt har mindre arbeidserfaring enn ledere ved sykehjem. I hjemmebaserte tjenester
Den normative verdipyramide (Orvik 2004)

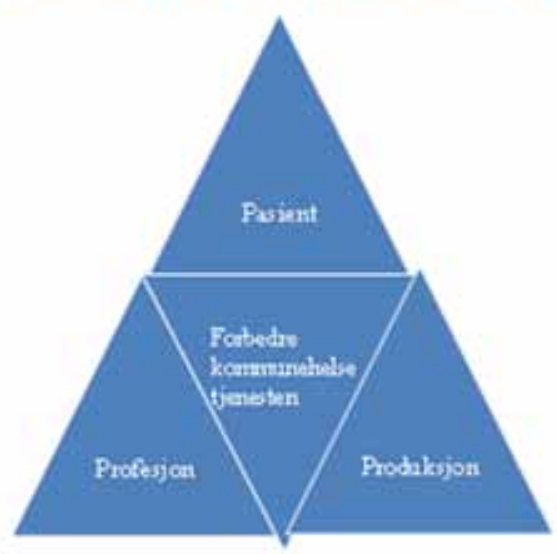

har ledere også gjennomsnittlig mindre ledelsesutdanning (3).

Kommunehelsetjenesten bør også ha flere spesialister innen pleie- og omsorgsfaglige områder. Spesialister innen geriatri, psykiatri, rusomsorg, ernæring og kreft trengs. Dette mest fordi tjenesten, i større grad enn tidligere, må legge vekt på forebyggende helsearbeid. Norge har, i alle fylker, både undervisningssykehjem og undervisningshjemmetjeneste som kan utvikle tjenester og vurdere nye løsninger.

Norsk forskning viser at det fortsatt er lite kompetanse på kreftlindring i kommunene (5). Det bør i alle fall være tilsatt en kreftsykepleier på hver enhet eller avdeling fordi sektoren innen dette feltet skal ha kunnskap om blant annet smertelindring og omsorg mot livets slutt. 


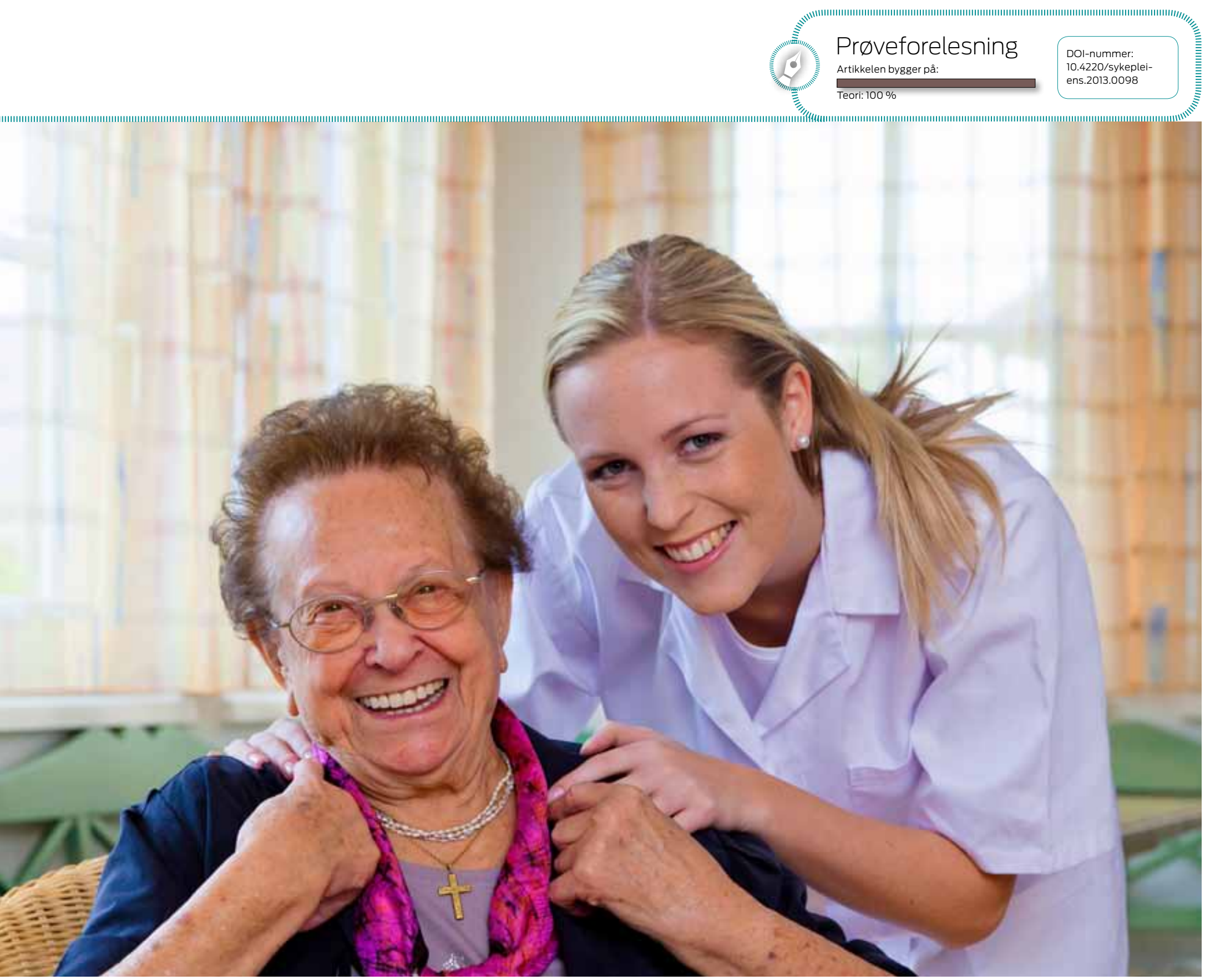

FLERE TILTAK: Økt kompetanse innen ledelse, spesialisering og pedagogikk blant de ansatte i kommunehelsetjenesten vil gi et bedre tilbud til brukerne. Illustrasjonsfoto: Colourbox.

Abrahamsen (6) har undersøkt små stillingsbrøker i sektoren og fant at små stillinger ikke er positivt verken for pleier eller pasient. Det er også en klar sammenheng mellom utdanningsnivå, plan om å gjennomføre en videreutdanning og små stillingsbrøker i kommunehelsetjenesten. Små stillingsbrøker kan derfor være en medvirkende årsak til lite kompetanseheving blant helsefagarbeiderne.

\section{Flere må utdannes}

Det utdannes altfor få helsefagarbeidere i den videregående skole til å dekke det økte behovet i fremtiden og erstatte hjelpepleiere og omsorgsarbeidere som etter hvert går av med pensjon. Det viser en rapport om tilbud og etterspørsel av helse- og sosialpersonell frem mot 2030 (7). Dette gjelder særlig helsefagarbeidere, men også sykepleiere. Abrahamsen (6) mener hjelpepleierne tapte sin posisjon på 90-tallet, da hjelpepleiere skulle ut av sy- kehusavdelingene samtidig med at vi fikk nye læringsreformer i skolen.

Hjelpepleiere arbeider svært selvstendig i hjemmesykepleien og gjør om lag de samme oppgavene som sykepleierne. Dette endrer seg når det gjelder arbeidet ved sykehjemmene. Der er det sykepleiere og ikke hjelpepleiere som er ledere og har hovedansvaret. Det kan være at pasientgruppen er mer skrøpelig der, men ikke nødvendigvis. Undersøkelser viser at det er lite forskning i Norge på hjelpepleierens utvikling, arbeidsliv og arbeidsvilkår. Oppsummert kan det se ut som om hjelpepleier best utvikles rent faglig i hjemmebasert tjeneste (8).

\section{Samhandlingsreformen}

Mange av helse- og sosialtjenestens utfordringer på produksjonsnivå knytter seg til forhold rundt styring og finansiering på systemnivå. Dette er problemstillinger som til dels vil være spesifikt norske, dels universelle.

Samhandlingsreformen (9) har som overordnet mål å styrke samhandling i sektoren og koordinere tjenestetilbudene bedre. Romøren er kritisk til samhandlingsreformen og

\section{"Kommunehelsetjenesten bør ha flere spesialister.»}

indikerer at reformen ikke nødvendigvis er til det beste for pasientene. Det er en oppgavefordeligsreform på systemnivå som innskrenker sykehusets oppgaver, og kommunehelsetjenesten overtar en del av dette arbeidet. Dette skal være kostnadseffektivt. Noen kommuner mestrer dette godt, mens andre kommuner mestrer det i mindre grad. Romøren peker på at reformen er basert på lite forskning, at den kun er norsk og at tre av fem undersøkelser er gjort av samme forfatter (10). 


\section{Pedagogisk endring}

Forskning viser også at helsetjenester må ha forståelse for og avklare karakteristikkene av tverrprofesjonell samhandling i helse- og sosialfagutdanninger og i helsetjenesten. En pedagogisk endring så vel som endring i helsetjenestens kultur er nødvendig for at politikken rundt tverrprofesjonell omsorg skal lykkes. En slik endring i holdninger, verdier, filosofi og kultur i helsevesenet må begynne på utdanningsnivå.

Canadisk forskning viser at utdanning hittil har vært preget av studentens individuelle kunnskap, men at dette bør endres til et perspektiv der helse- og sosialfagstudenter erkjenner at deres prestasjoner, sammen med andre yrkesgrupper, er viktig for pasientens helhetlige omsorg (11).

En svensk studie fant tre generelle barrierer for tverrprofesjonell samhandling: Kun prioritering av egen organisasjon, mangel på kommunikasjon og usikkerhet. Alle er knyttet dels til organisatoriske endringer generelt, og dels til spesifikk utvikling av tverrprofesjonell kompetanse (12).

Fra 2007-2012 var åtte høyskoler og universiteter i Norge med på prosjektet Collaboration Across Professional Boundaries (CAB). Prosjektets mål var å kartlegge i hvilken grad helse- og sosialfagutdanningene forbereder sine studenter på tverrprofesjonell samhandling (TPS). CAB-prosjektet initierte og prøvde ut mulige småskalamodeller for TPS og evaluerte slike tiltak og prosesser. Ingen utdanningsinstitusjon har per i dag innført dette i full bredde på systemnivå, men det er på gang. Det ble skrevet ni delrapporter fra prosjektet i tillegg til artikler (13).

Både internasjonalt og innen Norden opplever man et økende TPS-engasjement. Det er blitt etablert flere TPS-nettverk, både i Norge, Norden og på tvers av verdensdeler, med årlige konferanser og eget forskningstidsskrift. Canada og Storbritannia er foregangsland og har inspirert land i Norden.

\section{Terapeuter i sykehjem}

Forskning viser at dagens eldreomsorg styres mot en prioritering av medisinske oppgaver. Det er i tråd med New Public Management ideologien og rapporteringssystemet i kommunene. Sykehjemmene skal fokusere på korttidsplasser, rehabilitering og terminal pleie. Det blir i mindre grad lagt til rette for flere faste langtidsplasser i enhetene. En konklu- sjon indikerer at de ansatte ikke er flinke nok til å finne helsefremmende ressurser hos pasientgruppene, det lille som er igjen, men heller bruker medisiner.

Jakobsen og Granbo presiserer at terapeuter i større grad bør ansettes i sykehjem. Ved å bruke terapeuter kan tjenesten maksimere beboernes funksjonsnivå både mentalt og fysisk. Terapeuter kan være utdannet fysioterapeut, ergoterapeut, sosionom, vernepleier og så videre. Miljøterapi kan i større grad fokusere på frokostgrupper, trim og dansegrupper, spill, sang, husarbeid og andre aktiviteter (14).

Pleie- og omsorgspersonell kan ha lite kjennskap til hvilke tilbud terapeutgruppen kan bidra med og ofte ser man et underforbruk av disse tjenestene i sektoren. Ergoterapi og fysioterapi kan ha så stor effekt for pasientens helse at det reduserer behovet for pleie og omsorgstjenester. Dette kan videre føre til mindre deprimerte pasienter og mindre bruk av antidepressive preparater (14).

\section{Andre tiltak}

Norsk forskning viser at 44 av 58 pasienter fra hjemmesykepleien ikke vet når pleieren kommer. De får heller ikke selv bestemme når pleieren skal komme. Avtaler når det gjelder andre aktiviteter blir dermed vanskelig å få fastsatt (15).

Det er ikke nødvendig å være terapeut for å motivere pasienten til aktivitet. Det er heller ikke nødvendig å bruke pleiepersonalet til all aktivitet. Familie, venner, frivillighetssentral, besøkstjeneste, diakon, Røde Kors og støttekontakt kan brukes mer.

Fysisk aktivitet kan best utføres utendørs. Man kan sikre utearealer slik at demente personer kan oppholde seg i hagen. Hagen kan stimulere beboerne og bidra til bevegelsesfrihet, trening og hagearbeid. Dyr kan også være en del av hagen. Godt lys gir bedre søvn.

En amerikansk feltstudie deler pasienter med demenssykdom som bor i sykehjem inn i tre grupper. Den ene gruppen fikk en 30 minutters samtale, den andre fikk 30 minutters spasertur. Den tredje gruppen fikk både 30 minutters spasertur med samtale på hele turen. Denne aktiviteten pågikk tre ganger i uken over fire måneder. Spasertur eller annen fysisk aktivitet i tillegg til samtale gjorde personer med demens langt mer delaktige i samtalen (16).

Ny forskning, der fem kommuner deltar i prosjektet Trygge Spor sammen med Sintef, prøver ut GPS-sporing av demente personer. Det er meningen at bruker og pårørende kan være mer fri og den demente kan gå ute alene. I Danmark bruker 82 av 98 sykehjem GPS til brukere med demens (17).

\section{Oppsummering}

Oppsummert viser dette at profesjonsperspektivet, produksjonsperspektivet og pasientperspektivet må sees under ett. Skal en organisasjon forbedres er det vanskelig å prioritere et perspektiv alene. Artikkelen vektlegger kommunehelsetjenesten og har prioritert noen tiltak; utvikling av profesjoner, tverrprofesjonell fokus i tjenesten og pasienters egenaktivitet. Dette fordi slike tiltak samlet kan styrke kommunehelsetjenesten og er i tråd med Stortingsmelding 47, 2008-2009. IIII

\section{REFERANSER:}

Orvik A. Organisatorisk kompetanse - i sykepleie og helsefaglig samarbeid. Oslo: Cappelen Akademisk Forlag, 2004.

2. Vasset $F$, Marnburg E, et al. «Employees) perceptions of justice in performance appraisal.») Nursing Management 2010;17: 30-4.

3. Decker FH, Decker SL. «Experience and education of home health administration and nursing home administration and the relationship to ministration and nursing home administration and the relationship to
established ownership.y Journal of Health and Human Service Administration. 2012; 35:149-169.

4. Hasson H, Arentz J.E. «Nursing staff competence, work strain, stress and satisfaction in elderly care, a comparison of home-based care and nursing homes.) Journal of Clinical Nursing 2008; 17:468-81.

5. Hynne AB, Kvangarsnes M. «Å vere kreftsjukepleiar i kommunehelsetjenesta - ein intervjustudie om funksjoner og yrkesrolle.» Vård i Norden. 2012; 103: 27-31.

6. Abrahamsen B. Hvorfor utdanne to pleiere for å få en? Oslo: Pax forlag, 2002.

7. Texmon I, Stølen NM. Arbeidsmarkedet for helse- og sosialpersonell frem mot år 2030. HELSEMOD. Oslo: Statistisk sentralbyrå, 2009/9.

8. Eriksen W. «Practice area and work demands in nurses aides; a crosssectional study.» BMC Public Health 2006; 6: 97.

9. St.meld. 47. (2008-2009). Samhandlingsreformen. Rett behandling - på rett sted - til rett tid. Helsedepartimentet. Oslo.

10. Romøren TI. Samhandlingsreformen - et kritisk blikk på en helsereform. Idun.no - tidsskrift på nett, Nordisk sygeplejeforskning 2011/1.

11. Karim R. «Buildinginterprofessional framework through educational reform.y Journal of Chiropractic Education - Spring 2011; 25:38-43.

12. Andersen J, Ahlgren B, et al. «Organization approaches to collaboration in vocational rehabilitation - an international literature review.») International Journal of Intergrate Care 2011;1:1:-9.

3. Bjørke G, Almenning T, et al. Kvalifisering for tverrprofesjonelt samarbeid i helse- og sosialsektoren. Småskrift. Oslo: HIOA, 2012.

4. Jakobsen K, Granbo R. «Større faglige bredde bidrar til mer aktiv omsorg for sykehjemsbeboerne.») Forskning 2011; 2(6): 142-58.

15. Grevjon E.R. Kontinuitet i hjemmetjenesten - en foreløpig rapport basert på intervjuer med tjenestemottakere, pårørende og ledere. Senter for omsorgsforskning. S. f. omsorgsforskning. Gjøvik: Høgskolen i Gjøvik. 2009.

16. Tapper R, Roach K, et al. (2000). «Effect of combined walking and intervention on functional mobility of nursing home residents with alzeimers disease.n) Alzheimer Dis Assoc Disord. 2000; 14(4): 196-201.

17. Ausen D, Svagård I, et al. Trygge spor. A20663. Trondheim: Sintef, 2012. 